\title{
TU/e EmonOWEN

\section{A comparative study of learning patterns of secondary school, high school and college students}

\section{Citation for published version (APA):}

Song, Y., \& Vermunt, J. D. (2021). A comparative study of learning patterns of secondary school, high school and college students. Studies in Educational Evaluation, 68, [100958].

https://doi.org/10.1016/j.stueduc.2020.100958

\section{Document license:}

TAVERNE

DOI:

10.1016/j.stueduc.2020.100958

Document status and date:

Published: 01/03/2021

\section{Document Version:}

Publisher's PDF, also known as Version of Record (includes final page, issue and volume numbers)

\section{Please check the document version of this publication:}

- A submitted manuscript is the version of the article upon submission and before peer-review. There can be important differences between the submitted version and the official published version of record. People interested in the research are advised to contact the author for the final version of the publication, or visit the $\mathrm{DOI}$ to the publisher's website.

- The final author version and the galley proof are versions of the publication after peer review.

- The final published version features the final layout of the paper including the volume, issue and page numbers.

Link to publication

\section{General rights}

Copyright and moral rights for the publications made accessible in the public portal are retained by the authors and/or other copyright owners and it is a condition of accessing publications that users recognise and abide by the legal requirements associated with these rights.

- Users may download and print one copy of any publication from the public portal for the purpose of private study or research.

- You may not further distribute the material or use it for any profit-making activity or commercial gain

- You may freely distribute the URL identifying the publication in the public portal.

If the publication is distributed under the terms of Article 25fa of the Dutch Copyright Act, indicated by the "Taverne" license above, please follow below link for the End User Agreement:

www.tue.nl/taverne

Take down policy

If you believe that this document breaches copyright please contact us at:

openaccess@tue.nl

providing details and we will investigate your claim. 


\title{
A comparative study of learning patterns of secondary school, high school and college students
}

\author{
Yu Song ${ }^{\mathrm{a}, \mathrm{b}, *}$, Jan D. Vermunt ${ }^{\mathrm{c}}$ \\ ${ }^{a}$ School of Education, South China Normal University, No. 55 Zhongshan Road, Tianhe District, Guangzhou, Guangdong Province, 510631, China \\ ${ }^{\mathrm{b}}$ Institute for Advanced Study of Educational Development in Guangdong-Hong Kong-Macao Greater Bay Area, South China Normal University \\ ${ }^{\mathrm{c}}$ Eindhoven School of Education, Eindhoven University of Technology, Groene Loper 3, 5612 AE, Eindhoven, the Netherlands
}

\section{A R T I C L E I N F O}

\section{Keywords:}

Learning patterns

Cross-educational differences

Learning strategies

Dimensionality

Personal and contextual factors

\begin{abstract}
A B S T R A C T
The main aim of the current research was to identify the similarities and differences in learning patterns used by secondary school, high school and college students. There were 8,072 participants and they responded to the Chinese version of Inventory of Learning Styles (ILS) online. Findings show that the three groups of students were significantly different in their adoption of learning patterns; the dimensionalities of learning patterns observed in secondary school and high school students were similar, but were different from those of college students; these students' learning patterns differed from each other in relation to personal characteristics (i.e. gender and age), but tended to have similar strong relationships with parents' education level and parents' jobs. This study contributes to the understanding of the learning patterns characterized by school and college students. By acknowledging this, educators can help to develop better support for students in adapting to new study environments.
\end{abstract}

\section{Introduction}

A learning pattern is conceptualized as "a coherent whole of learning activities that learners usually employ, their beliefs about learning and their learning motivation, a whole that is characteristic of them in a certain period of time" (Vermunt \& Donche, 2017, p. 270). Learning patterns capture differences in student learning and characterize people's habitual approaches, methods or strategies with respect to thinking and learning. Different educational stages require students to use a variety of learning strategies (Coertjens, Donche, Maeyer, Van Daal, \& Van Petegem, 2017). Students often encounter difficulties in adapting to a new teaching and learning environment when they move from a lower to a higher stage of education, and some of them may experience academic failure or dropout problems (OECD, 2018). Effective instruction and tutoring are required in order to help students develop and improve upon appropriate learning strategies in a specific educational context (Gijbels, Donche, Richardson, \& Vermunt, 2014). There is a clear need to learn about the learning patterns that are characteristic of students at different stages of their education. Publications on learning patterns have increased in number over the last two decades (Vermunt \& Donche, 2017; Vermunt \& Vermetten, 2004), reflecting their theoretical and practical value in research and applied settings. There are cross-cultural studies comparing learning patterns of students from different countries (e.g. Marambe, Vermunt, \& Boshuizen, 2012; Vermunt, Bronkhorst, \& Martinez-Fernandez, 2014), yet few of them have conducted cross-sectional comparisons between students at various educational stages. This study aims to examine the similarities and differences in learning patterns amongst secondary school, high school and college students.

\subsection{Research on learning patterns}

Until about two decades ago, the majority of student learning research and conceptualizations mainly focused on cognitive processing strategies and motivation, for example, the well-known Student Approaches to Learning framework (SAL). Some others focused on metacognition, which developed into the research tradition of Self-Regulated Learning (SRL). The learning pattern perspective proposed by Vermunt and Vermetten (2004) is a holistic and broad framework that not only brings together these different research traditions but also explores their interrelationships. In the framework, four interrelated components are united to characterize student learning: cognitive processing strategies, metacognitive regulation strategies, conceptions of learning, and learning motivations or orientations. Cognitive processing strategies

\footnotetext{
* Corresponding author.

E-mail addresses: sungyuepku@foxmail.com (Y. Song), j.d.h.m.vermunt@tue.nl (J.D. Vermunt).
} 
refer to the activities that student employ to process subject matter for the purpose of acquiring knowledge, understanding and skill. Regulation strategies are the activities that reflect students' sense of metacognition when planning, monitoring, steering and evaluating learning processes. Conceptions of learning are the beliefs and views students hold about learning, teaching and related phenomena. Learning motivations or orientations encompass a whole domain of aims, motives, goals and worries that students have about their studies. Based on a series of quantitative and qualitative studies, the four components have been operationalized into the ILS Inventory (Vermunt, 1998, 2020). Its construct and scales are exhibited in Appendix A. There are a number of foci in relation to the research on learning patterns, some of which are discussed below.

\subsubsection{Adoption of learning patterns}

Learning patterns are conceived as relatively stable but are amenable to change over time in response to the changes in physical and sociocultural environments (Donche \& Gijbels, 2013; Evans \& Vermunt, 2013). Considering its malleability, Vermunt (2005) introduced the terminology 'learning pattern' to take the place of 'learning style'. Findings from longitudinal studies indicate that learning patterns are dynamic and subject to development. For example, Coertjens et al. (2017) reported a growing trend in the use of learning strategies during the transition from secondary school to higher education. Self-regulation strategies were found to increase during the transition, and so was depth of analysis. In addition, learning patterns tend to differ according to cultural context. Vermunt et al. (2014) compared means for scales of learning patterns between university students in eight countries (areas), namely, Hong Kong, Colombia, Indonesia, Mexico, Spain, Sri Lanka, The Netherlands and Venezuela. Significant mean differences were identified not only between continents, but also between areas within a continent. For example, Hong Kong students had lower scores for critical processing, analysing, and concrete processing than Colombian students, and for relating and structuring than the Dutch students. Almost half of the learning patterns scales were found to vary significantly between two Asian countries, Sri Lankan and Indonesian.

\subsubsection{Dimensionality}

The ILS inventory was originally tested in higher education in North European countries, for example, The Netherlands, United Kingdom, Finland and Belgium (Vermunt \& Donche, 2017). In most of these studies, four distinct learning patterns emerged based on factor analyses: meaning-directed, reproduction-directed, application-directed and undirected learning (Lonka, Olkinuora, \& Mäkinen, 2004; Vermunt, 1998). People who are characterized with a meaning-directed learning pattern tend to employ deep-processing and self-regulated strategies, view learning as the personal construction of knowledge and learn out of personal interest. Reproduction-directed learning features in the use of stepwise processing and external-regulation strategies, and is an embodiment of a learning conception in which learning is seen as the intake of knowledge and of a learning orientation in which self-testing and obtaining certificates are stressed. Students who adopt an application-directed learning pattern prefer to use concrete processing strategies, employ both self- and external regulation strategies, view learning as a process of application of knowledge, and have a vocation-directed orientation. Students characterized with an undirected learning pattern have difficulties in processing knowledge, relies heavily on teacher direction and peer cooperation, show lack of regulation, are ambivalent in their learning motivation and attach a lot of value in their learning conception to stimulating education and peer cooperation.

Owing to high reliability and validity, the ILS has been further translated into different languages, and employed with students and student teachers in a broader array of cultural contexts (Vermunt \& Donche, 2017). These include Asian countries, for example, Thailand (Eaves, 2009) and China (Law, 2009), and South American countries like Argentina (Alves de Lima et al., 2006), Colombia, Mexico and Venezuela (Martínez-Fernández \& Vermunt, 2015). The majority of these studies have a focus on higher education, covering universities, adult education and professional contexts (Gijbels et al., 2014). Marked differences have been identified in relation to the dimensionality and interrelations among scales (Gijbels et al., 2014). Vermunt et al. (2014) compared the dimensionality of learning patterns identified in eight countries (areas). They found distinctive differences in relation to the dimensionality of learning patterns of students from different cultures, as follows: 1) A set of scales relating to processing and regulation strategies typical of meaning-directed learning highly loaded on one factor. External regulation strategies also show loadings on this factor in some cases (e.g. Indonesia). A number of conception and orientation scales highly loaded on this factor in some cases (e.g. the Dutch), while being absent in others (e.g. Hong Kong); 2) A passive-idealist pattern, that is, all conceptions of learning showed loadings on a factor with no scales from other components, was identified in seven cases, except the Dutch; 3) The reproduction-directed and undirected learning patterns were clearly visible in all cases; 4) The application-directed pattern was not recognized in most cases except The Netherlands and Finland; 5) In some cases (e.g. Mexico), a number of scales in relation to learning orientation typically loaded on one factor while no scales of other components appeared, and this was referred to as a passive-motivational learning pattern.

\subsubsection{Relationships with personal and contextual factors}

Students' learning patterns have been found to be related to, or influenced by, various personal and contextual factors (Vermunt \& Donche, 2017). Among the personal factors are prior education, age, gender (Vermunt, 2005) personality (e.g. Fryer, Ainley, \& Thompson, 2016), academic motivation (e.g. Catrysse, Coertjens, Donche, van Daal, \& Van Petegem, 2015), goal orientation (e.g. De Clercq, Galand, \& Frenay, 2013), attributions of academic success (Ferla, Valcke, \& Schuyten, 2008), self-efficacy (e.g. Heikkilä, Niemivirta, Nieminen, \& Lonka, 2011), effort (e.g. Martínez-Fernández \& Vermunt, 2015), and epistemological and intelligence beliefs (Stump, Husman, \& Corby, 2014). Gender, age and prior education are three of the factors that are most frequently studied. With regard to gender, Law and Meyer (2011) identified its relationship with learning patterns using a sample of Hong Kong university students. Male students were identified as active learners as they achieved higher scores on four of the five processing strategy scales (except memorizing) and on both self-regulation scales. Female students were shown to be rather passive as their scores were higher on four of the five learning-conception scales (except cooperative learning) and four of the five learning-motivation scales (except ambivalence). Age has also been found to be predictive with respect to learning patterns. For example, Vermunt (2005) examined the relationship among university students in the Netherlands and found that the older students were, the more likely they were to adopt the meaning-directed pattern. Regarding prior education, a typical feature identified was that students were less likely to adopt reproduction-directed learning when their prior education was at a high level (Vermunt, 2005).

Contextual factors include teaching methods (e.g. Donche, De Maeyer, Coertjens, van Daal, \& van Petegem, 2013), perception of the learning environment (e.g. Law \& Meyer, 2011), and disciplinary differences (e.g. Smith, Ray, Stefurak, \& Zachar, 2007). Students' learning patterns were significantly associated with teachers' teaching methods. For example, based on 90 lecturers and 1,126 undergraduate students, Donche et al. (2013) found that students were likely to obtain high scores in processing strategies and regulation strategies when their teachers were more learning focused. Students' perceptions of the learning environment, including teaching and assessment, had a direct or indirect relationship with their learning patterns (e.g. Law \& Meyer, 2011). Students tend to vary in their adoptions of learning pattern when they are from different disciplines. Vermunt (2005) compared the 
learning patterns of students from seven disciplines at a Dutch university. Students in Arts and Psychology disciplines tended to use of meaning-directed learning while they were not likely to adopt a reproduction-directed learning pattern. The latter way of learning was identified most among students of Law and Economy. Lindblom-Ylänne and Lonka (2000) found that advanced and adult medical students attached a high value to application-directed learning. Timarova and Salaets (2011) showed that applied language students favoured the use of a reproduction-directed learning pattern.

\subsection{Identifying gaps and aims of the current research}

Having reviewed the literature, there appeared to be several gaps waiting to be filled by further studies. Firstly, research on learning patterns has been mostly based on higher education, while students of school age, for example, secondary school and middle high school, have been covered to a lesser extent. Moreover, comparative studies have been previously conducted in order to examine cross-cultural differences in student learning patterns. There are much fewer cross-sectional studies comparing learning patterns of students at different stages of education. Thirdly, in previous studies, scholars have mainly focused on contextual factors in school settings, while neglecting the influence of families. Given the important role of parents in students' growth and development, parental factors may be possible components of contextual factors that are related to students' learning patterns.

To address the above gaps, the main aim of the current study was to compare the learning patterns identified with respect to secondary school, high school and college students. Specifically, it sought to answer that following questions: (1) What are the similarities and differences in learning patterns between these three groups of students? (2) What are the similarities and differences with regard to the dimensionalities of learning patterns of these students? (3) What are the similarities and differences concerning the relationships of learning patterns to personal and contextual factors? A number of traditionally studied factors (i.e. gender and age) along with several less frequently studied factors (parents' education, parents' jobs) were examined.

\section{Methods}

\subsection{Participants}

Fifty-three schools and colleges were involved, comprising $30 \mathrm{sec}-$ ondary schools, 20 high schools and three colleges. Secondary school and high school are two successive education periods, and are compulsory for all students in mainland China. After finishing high school, students either apply to universities or colleges, with the former being more academically directed and the latter, more practically oriented. In each school/college, at least three classes were selected for study. Students in the selected classes acted as participants unless they expressed a wish not to take part. There were 8,072 students who participated in the online survey, comprising 5,333 secondary school students, 2,478 high school students and 261 college students. Age groups for the secondary school, high school, and college students were years 13-15, 16-18 and 19-21, respectively. Male students accounted for 41.1 per cent of the total number, female students constituted 54.6 per cent, while the remaining students were reluctant to disclose their gender. All participants were Chinese.

\subsection{Instruments}

The Chinese version of the ILS was used to measure participants' learning patterns. The instrument comprises 120 items and after each item, there is a 5-point Likert-type scale for self-rating, ranging from 1 to 5 , with 1 indicating that the description does not at all represent the way one normally behaves or views, and 5 indicating that the statement characterizes fully accurately how one tends to behave and view.
Besides the instrument, several questions were added beforehand to obtain demographic information, namely, gender, age, disciplines, parents' education levels and parents' jobs. Parent's educational experience was divided into eight levels: no education experience, primary school, secondary school, high school, college, bachelor's, Master's and $\mathrm{PhD}$. The classification of parents' job was compatible with Chinese official statistics, which comprise 11 categories: senior technicians, junior technicians, governmental officials, senior executives of businesses, middle and low managers in businesses, workers/builders/drivers, soldiers/officers, farmers, servants/salesmen/shop assistants, retired and unemployed. It should be noted that students' names were not asked in order to protect their confidentiality. We attached the questions and instrument to an online platform and students with access to the Internet were able to participate in the survey, which was not limited by geographical location.

\subsection{Analysis}

Cronbach's alphas for scales of learning patterns were calculated in order to estimate whether the ILS was reliable when it came to students' learning patterns in the Chinese context. Subsequently, means and standard deviations for the scales of three student groups were calculated respectively, which provided an initial description of the central tendency and dispersion of the data. The mean scale scores of the three groups were then compared by using MANOVA. This method is useful when assessing whether there are any differences between independent groups with regard to more than one continuous dependent variable, and the dependent variables are moderately correlated with each other. Bonferroni corrections were run to correct for the number of significance tests ( $p=.05$ divided by the number of comparisons). Scheffé post-hoc analyses were applied to identify which of the student groups differed from each other, in the case of a significant overall F-value. Next, exploratory factor analyses were conducted with secondary school, high school and college students respectively to assess the internal relationships of learning patterns. The oblique rotation method was used as learning patterns are not mutually exclusive with respect to the constituent scales (Vermunt \& Donche, 2017). We then compared factor loadings of the inventory scales for the three student groups. Finally, the relationships between learning patterns, including sub-scales of learning patterns and clustered factors, with a set of personal (i.e. age, gender) and contextual factors (i.e., parents' education level, jobs and disciplines), were investigated for the three student groups separately by using MANOVAs.

\section{Results}

\subsection{Adoption of learning patterns}

As shown in Table 1, Cronbach's alphas for the scales of learning patterns were high in the range of .71-.98, indicating a good internal reliability of the ILS and its suitability to work with secondary school, high school and college students.

Multivariate tests indicated that there was a statistically significant difference in learning patterns between secondary school, high school and college students. The Box's M test indicated that homoscedasticity of the dependent variables was not verified $(\mathrm{F}=4.53$, $\mathrm{sig}<.001)$. The value for Pillai's Trace was then reported, which was 0.095 with significant levels below 0.001 . The measures of effect size for the learning patterns based on education sections were generally moderate, expect for external regulation strategies, intake of knowledge, use of knowledge and personally interested orientation, whose measures were small. In Table 2, means and standard deviations for the ILS scales for secondary school, high school and college students are shown, followed by $\mathrm{F}$ values and significance levels of the differences between the means. Twentythree MANOVA scale comparisons were significant, except for one scale, personally interested orientation, which did not show a significant 
Table 1

Cronbach's alphas for ILS scales for secondary school $(N=5333)$, high school $(N=2478)$ and college samples $(N=261)$.

\begin{tabular}{|c|c|c|c|}
\hline Inventory scales & Secondary & High & College \\
\hline \multicolumn{4}{|l|}{ Processing strategies } \\
\hline Deep processing & .92 & .89 & .93 \\
\hline Relating and structuring & .87 & .87 & .93 \\
\hline Critical processing & .83 & .89 & .88 \\
\hline Stepwise processing & .91 & .88 & .94 \\
\hline Memorizing and rehearsing & .81 & .80 & .86 \\
\hline Analysing & .85 & .74 & .87 \\
\hline Concrete processing strategy & .84 & .82 & .93 \\
\hline \multicolumn{4}{|l|}{ Regulation strategies } \\
\hline Self-regulation & .93 & .92 & .93 \\
\hline Learning processes and results & .90 & .89 & .86 \\
\hline Learning content & .82 & .79 & .86 \\
\hline External regulation & .88 & .84 & .91 \\
\hline Learning process & .80 & .71 & .81 \\
\hline Learning results & .78 & .72 & .86 \\
\hline Lack of regulation & .84 & .77 & .95 \\
\hline \multicolumn{4}{|l|}{ Conceptions of learning } \\
\hline Construction of knowledge & .92 & .90 & .91 \\
\hline Intake of knowledge & .87 & .83 & .93 \\
\hline Use of knowledge & .87 & .90 & .91 \\
\hline Stimulating education & .91 & .82 & .93 \\
\hline Cooperation & .88 & .84 & .88 \\
\hline \multicolumn{4}{|l|}{ Learning orientations } \\
\hline Personally interested & .79 & .75 & .87 \\
\hline Certificate directed & .77 & .74 & .82 \\
\hline Self-test directed & .82 & .78 & .86 \\
\hline Vocation directed & .81 & .76 & .84 \\
\hline Ambivalent & .82 & .78 & .84 \\
\hline
\end{tabular}

overall mean difference across three student groups. Regarding the scales of processing strategies, the means for the concrete processing strategy of the three groups were the highest. External regulation scales produced high means amongst the scales of regulation strategies. In terms of scales to measure learning orientation, the mean score for personally interested ranked top for the secondary school students; high school students obtained the highest mean score for self-testing orientation; college students scored highest for the vocation-directed orientation. Regarding conceptions of learning, the means for construction of knowledge were the highest for three groups. The college students also scored high in relation to the cooperation scale.

When Scheffe post-hoc tests were applied, significant overall mean differences resulted in a set of more specifically significant differences between student groups. Based on Bonferroni corrections, all differences referred to below are significant, but only the largest differences will be mentioned here. With regard to cognitive processing strategies, college students scored significantly higher than secondary school students on all scales, notably on critical processing ( 3.37 vs $3.02, p<.001)$ and analysing strategies ( 3.33 vs $3.04, p<.001$ ). The mean scores obtained by the high school students were also significantly higher than those of the secondary student group; nevertheless the differences were smaller. The college students used more critical processing strategies than the high school students ( 3.37 vs $3.15, p<.01$ ). Regarding regulation strategies, the mean scores for college students ranked top in all scales; those for high school students ranked the second in relation to selfregulation and external regulation strategies; and those for secondary school students were third in relation to self-regulation and external regulation strategies. In terms of conceptions of learning, high school students viewed learning more as construction of knowledge (4.02 vs $3.93, p<.05$ ), intake of knowledge (3.77 vs 3.72, $p<.05$ ), use of knowledge ( 3.94 vs $3.87, p<.01$ ), and stimulating education ( 3.53 vs $3.46, p<.001)$ than secondary school students. In comparison, the secondary students found cooperative learning more important than their high school counterparts did (3.83 vs 3.73, $p<.001$ ). Concerning learning orientations, the three groups scored equally high in relation to personal interest. The college students were more oriented towards gaining certificates than the secondary school students (3.72 vs 3.32, $p<.001)$ and the high school students were (3.72 vs $3.31, p<.001)$. The high school students were more self-testing oriented than their secondary counterparts $(3.77$ vs $3.66, p<.001)$. The secondary students were the least likely to hold a vocation-directed orientation compared to their high school (3.58 vs 3.71, $p<.001$ ) and college counterparts ( 3.58 vs $3.83, p<.001$ ).

Table 2

Means and standard deviation of ILS scales, F values and significance levels of the differences between the means based on MANOVA.

\begin{tabular}{|c|c|c|c|c|c|c|c|c|c|}
\hline \multirow[t]{2}{*}{ Scales } & \multicolumn{2}{|c|}{ Secondary } & \multicolumn{2}{|l|}{ High } & \multicolumn{2}{|c|}{ College } & \multirow[t]{2}{*}{$F$} & \multirow[t]{2}{*}{$p$} & \multirow[t]{2}{*}{$\eta^{2}$} \\
\hline & $M$ & $S D$ & $M$ & $S D$ & $M$ & $S D$ & & & \\
\hline \multicolumn{10}{|l|}{ Processing strategies } \\
\hline Deep processing & 3.07 & .71 & 3.19 & .83 & 3.34 & .82 & 24.68 & $* * *$ & .17 \\
\hline Relating and structuring & 3.12 & .72 & 3.22 & .85 & 3.26 & .81 & 16.82 & $* * *$ & .10 \\
\hline Critical processing & 3.02 & .80 & 3.15 & .91 & 3.37 & .90 & 27.73 & $* * *$ & .18 \\
\hline Stepwise processing & 3.08 & .67 & 3.21 & .80 & 3.33 & .82 & 29.45 & $* * *$ & .19 \\
\hline Memorizing and rehearsing & 3.11 & .70 & 3.24 & .84 & 3.33 & .83 & a23.53 & $* * *$ & .15 \\
\hline Analysing & 3.04 & .72 & 3.18 & .84 & 3.33 & .84 & 30.21 & $* * *$ & .21 \\
\hline Concrete processing strategy & 3.13 & .74 & 3.26 & .85 & 3.37 & .81 & 24.90 & $* * *$ & .16 \\
\hline \multicolumn{10}{|l|}{ Regulation strategies } \\
\hline Self-regulation & 3.02 & .76 & 3.16 & .86 & 3.34 & .86 & 28.85 & $* * *$ & .20 \\
\hline Learning processes and results & 3.00 & .80 & 3.16 & .89 & 3.35 & .88 & 36.30 & $* * *$ & .25 \\
\hline Learning content & 3.05 & .78 & 3.16 & .90 & 3.33 & .89 & 18.77 & $* * *$ & .12 \\
\hline External regulation & 3.13 & .60 & 3.19 & .75 & 3.35 & .76 & 10.82 & $* * *$ & .05 \\
\hline Learning process & 3.13 & .62 & 3.20 & .78 & 3.33 & .79 & 10.69 & $* * *$ & .05 \\
\hline Learning results & 3.13 & .68 & 3.18 & .81 & 3.36 & .79 & 9.01 & $* * *$ & .03 \\
\hline Lack of regulation & 3.00 & .69 & 2.94 & .85 & 3.23 & .85 & 13.58 & $* * *$ & .08 \\
\hline \multicolumn{10}{|l|}{ Conceptions of learning } \\
\hline Construction of knowledge & 3.93 & .74 & 4.02 & .58 & 3.97 & .75 & 13.75 & $* * *$ & .08 \\
\hline Intake of knowledge & 3.72 & .72 & 3.77 & .60 & 3.85 & .75 & 5.70 & $* *$ & .01 \\
\hline Use of knowledge & 3.87 & .74 & 3.94 & .60 & 3.95 & .74 & 7.40 & $* *$ & .02 \\
\hline Stimulating education & 3.46 & .64 & 3.53 & .52 & 3.45 & .65 & 11.47 & $* * *$ & .07 \\
\hline Cooperation & 3.83 & .73 & 3.73 & .64 & 3.97 & .75 & 24.39 & $* * *$ & .16 \\
\hline \multicolumn{10}{|l|}{ Learning orientations } \\
\hline Personally interested & 3.70 & .77 & 3.72 & .66 & 3.80 & .75 & 1.43 & & .00 \\
\hline Certificate directed & 3.32 & .84 & 3.31 & .73 & 3.72 & .76 & 20.77 & $* * *$ & .15 \\
\hline Self-test directed & 3.66 & .80 & 3.77 & .67 & 3.78 & .75 & 17.63 & $* * *$ & .11 \\
\hline Vocation directed & 3.58 & .79 & 3.71 & .65 & 3.83 & .72 & 29.58 & $* * *$ & .19 \\
\hline Ambivalent & 3.20 & .88 & 3.28 & .77 & 3.48 & .79 & 14.91 & $* * *$ & .08 \\
\hline
\end{tabular}




\subsection{Dimensionality of learning patterns}

We obtained a three-factor models for all three samples, and the three factors accounted for 80.37 per cent of the variances in the secondary school data set, 87.76 per cent in the high school data set and 86.67 per cent in the college data set. Pearson correlations between the three factors, namely Factor 1 with Factor 2, Factor 1 with Factor 3, and Factor 2 with Factor 3 are $0.519,0.448$ and 0.412 respectively. The Kaiser-Meyer-Olkin (KMO) value for the three samples were .96, .95 and .95 , respectively, with significance levels less than .001. In Table 3, factor loading of ILS-scales on three extracted and rotated factors are presented. Results of factor analyses based on secondary school and high school students were similar. For both samples, the first factor was dominated by all scales of processing strategies, self-regulation strategies and personally interested orientation, elements typical of meaningdirected learning, as well as external regulation strategies. All scales of learning conceptions, self-testing oriented, vocation-oriented and personally interested orientations, loaded highly on Factor 2. Similar kinds of loading appeared in earlier research (see Vermunt et al., 2014) and can be interpreted as a passive learning pattern since they only contain ideas and motivations with regard to learning but without exhibiting any activities. Factor 3 captured high loadings of ambivalence and a lack of regulation, recognised as undirected learning, together with a certificate-directed orientation. With regard to college students, the loadings of learning scales was slightly different from those based on school samples. The first factor was dominated by a set of scales of cognitive processing strategies and regulation strategies, interpreted as action-directed learning, as it contains only strategies that needed to put learning into effect. Factor 2 exhibited high loadings of learning conceptions and Factor 3 captured high loadings of learning orientations. These two loadings have been reported in previous studies and were interpreted as passive-idealistic and passive-motivated patterns, respectively (Vermunt et al., 2014).

\subsection{Relationships with personal and contextual factors}

Table 4 illustrates mean differences in learning patterns between secondary school, high school and college students based on gender, age, father's education level, mother's education level, father's job and mother's job. The influence of gender on learning patterns was quite different for each of the three student groups. For secondary school students, there was little or no significant difference based on gender when it came to memorizing and rehearsing, external regulation strategies, cooperative-learning conceptions and vocation-directed orientation. Apart from these, boys and girls showed significantly different tendencies with respect to the other scales of learning patterns. Similarly, gender was significantly related to most scales of learning patterns for high school samples except for intake of knowledge, use of knowledge, personally interested orientation and vocation-directed orientation. Regarding the relationships with age, secondary school students' learning patterns were significantly varied when they were of different ages. As regards to high school students, the variations in age tended to have only a small influence on their learning patterns, with only three scales (i.e. relating and structuring strategy, analysing strategy and intake of knowledge) showing significant results. This influence was further smaller for college students, with almost no scales showing a significant relationship with age.

Parents' education levels had significantly positive relationships with learning patterns for all three groups of students (see Table 4, Figs. 1 and 2). The correlations of parents' education levels with processing and regulation strategies are stronger than those with conceptions and orientations of learning.

As shown in Figs. 3 and 4, parents' jobs had strong significant relationships with all of the scales of learning patterns of the secondary school sample. In comparison, for the high school sample, there were significant differences in cognitive processing strategies, regulation strategies and certificate-directed orientation between students whose parents worked in different jobs. Fathers' jobs were significantly correlated with college students' cognitive processing strategies and

Table 3

Factor loadings of ILS scales in a 3-factor solution for secondary school (SE), high school (HI) and college samples (CO) (principal component analysis, oblique rotation: $-.30<$ loadings $<.30$ omitted).

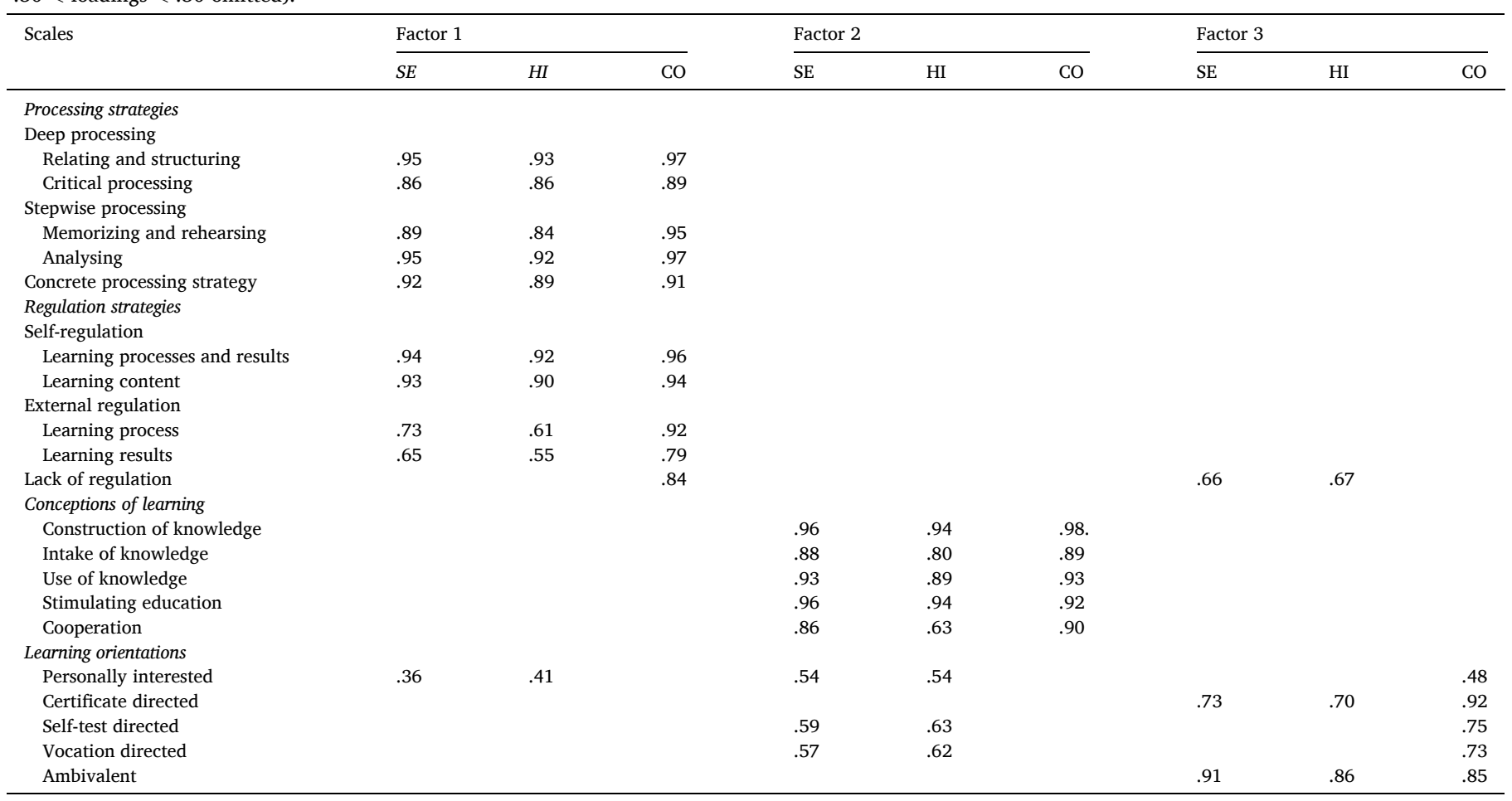


Table 4

Comparing mean differences on learning pattern scales between three student groups based on gender, age, parents' education levels and parents' jobs.

\begin{tabular}{|c|c|c|c|c|c|c|c|c|c|c|c|c|c|c|c|c|c|c|}
\hline \multirow[t]{2}{*}{ Scales } & \multicolumn{3}{|c|}{ Gender $(d f=1, F($ Sig. $))$} & \multicolumn{3}{|c|}{ Age $(d f=2, F($ Sig. $))$} & \multicolumn{3}{|c|}{$\begin{array}{l}\text { Father's education }(d f=8, F \\
\text { (Sig.)) }\end{array}$} & \multicolumn{3}{|c|}{$\begin{array}{l}\text { Mother's education }(d f=8, F \\
\text { (Sig.)) }\end{array}$} & \multicolumn{3}{|c|}{ Father's job $(d f=12, F($ Sig. $))$} & \multicolumn{3}{|c|}{ Mother's job $(d f=12, F(\mathrm{Sig}))}$. \\
\hline & SE & $H I$ & $\mathrm{CO}$ & $S E$ & $H I$ & CO & $S E$ & $H I$ & $\mathrm{CO}$ & $S E$ & $H I$ & $\mathrm{CO}$ & $S E$ & $H I$ & $\mathrm{CO}$ & $S E$ & $H I$ & $\mathrm{CO}$ \\
\hline \multicolumn{19}{|l|}{ Processing strategies } \\
\hline Deep processing & $15.05^{* * * *}$ & $66.93^{* * * *}$ & 0.41 & $14.23^{* * *}$ & 2.39 & 1.25 & $25.15^{* * * *}$ & $7.72 * * *$ & $6.15^{* * *}$ & $31.26^{* * * *}$ & $4.88^{* * *}$ & $3.91 * *$ & $14.20^{* * * *}$ & $5.90^{* * * *}$ & $3.91^{* * *}$ & $14.39^{* * * *}$ & $5.61^{* * *}$ & $2.44^{*}$ \\
\hline $\begin{array}{l}\text { Relating and } \\
\text { structuring }\end{array}$ & $7.94 * *$ & $33.53^{* * * k}$ & 0.23 & $12.63^{* * *}$ & $4.00^{*}$ & 0.99 & $22.83^{* * * *}$ & $7.51^{* * *}$ & $6.14^{* * * *}$ & $27.93^{* * * *}$ & $4.80^{* * *}$ & $3.50 * *$ & $12.55^{* * * *}$ & $3.90 * * *$ & $3.91 * * *$ & $12.45^{* * * *}$ & $4.70^{* * *}$ & $2.98^{* *}$ \\
\hline Critical processing & $20.12^{* * * *}$ & $87.11^{* * * *}$ & 0.54 & $13.01^{* * *}$ & 0.92 & 1.77 & $22.58^{* * * *}$ & $6.30 * * *$ & $5.27^{* * *}$ & $28.27^{* * * *}$ & $3.96^{* * * *}$ & $3.74 * *$ & $13.17^{* * * *}$ & $6.65^{* * *}$ & $3.56^{* * *}$ & $13.64^{* * * *}$ & $5.52^{* * *}$ & $1.89^{*}$ \\
\hline Stepwise processing & 0.86 & $37.32^{* * * k}$ & 0.04 & $19.50 * * *$ & $3.28^{*}$ & 1.46 & $24.46^{* * * *}$ & $5.53^{* * *}$ & $6.59^{* * *}$ & $28.32^{* * * *}$ & $5.15^{* * * *}$ & $3.83^{* *}$ & $13.22^{* * * *}$ & $3.77^{* * *}$ & $3.69 * * *$ & $12.09^{* * * *}$ & $4.16^{* * * *}$ & $2.61^{* *}$ \\
\hline $\begin{array}{l}\text { Memorizing and } \\
\text { rehearsing }\end{array}$ & 1.45 & $13.31^{* * * *}$ & 0.01 & $15.65^{* * *}$ & 2.01 & 0.84 & $21.10^{* * * *}$ & $2.75^{* *}$ & $6.03^{* * *}$ & $24.53^{* * * *}$ & $3.33^{* *}$ & $4.19^{* * *}$ & $11.48^{* * * *}$ & $2.68^{* *}$ & $3.66^{* * *}$ & $10.46^{* * * *}$ & $2.64 * *$ & $2.66^{* *}$ \\
\hline Analysing & $8.96^{* * *}$ & $60.31^{* * * *}$ & 0.08 & $20.13^{* * *}$ & $4.01 *$ & 2.10 & $23.58^{* * * *}$ & $7.73 * * *$ & $6.46^{* * * *}$ & $27.19^{* * * * *}$ & $6.10^{* * * *}$ & $3.22^{* *}$ & $12.77^{* * * *}$ & $4.11^{* * *}$ & $3.41^{* *}$ & $11.76^{* * * *}$ & $4.99^{* * * *}$ & $2.32^{*}$ \\
\hline $\begin{array}{l}\text { Concrete processing } \\
\text { strategy }\end{array}$ & $12.62^{* * * *}$ & $50.66^{* * * *}$ & 0.03 & $12.10^{* * *}$ & 2.50 & 2.28 & $22.82^{* * * *}$ & $5.50^{* * *}$ & $5.84^{* * *}$ & $29.72^{* * * *}$ & $3.78^{* *}$ & $4.51^{* * *}$ & $14.38^{* * * *}$ & $4.60^{* * *}$ & $3.24 * *$ & $14.66^{* * * *}$ & $4.03^{* * *}$ & $2.38^{*}$ \\
\hline \multicolumn{19}{|l|}{ Regulation strategies } \\
\hline Self-regulation & $7.85^{* *}$ & $47.93^{* \ldots * k}$ & 1.40 & $17.73^{* * *}$ & 2.13 & 1.69 & $23.16^{* * * *}$ & $8.82 * * *$ & $5.97 * * *$ & $28.23^{* * * *}$ & $5.43^{* * *}$ & $3.95^{* *}$ & $13.41^{* * * *}$ & $4.48^{* * *}$ & $3.03^{* * *}$ & $13.87^{* * * *}$ & $5.09 * * *$ & $1.98^{*}$ \\
\hline $\begin{array}{l}\text { Learning processes } \\
\text { and results }\end{array}$ & $11.78^{* * *}$ & $61.34^{* * * *}$ & 1.22 & $26.64^{* * *}$ & 2.29 & 2.63 & $20.42^{* * * *}$ & $8.66^{* * *}$ & $5.69^{* * * *}$ & $28.15^{* * * *}$ & $5.28^{* * *}$ & $3.67^{* *}$ & $12.62^{* * *}$ & $4.53^{* * *}$ & $2.81 * *$ & $12.91^{\text {**** }}$ & $4.96^{* * *}$ & $2.34^{*}$ \\
\hline Learning content & $3.89 *$ & $29.22^{* * * *}$ & 1.43 & $10.04^{* * *}$ & 1.65 & 0.88 & $18.73^{* * * *}$ & $7.81^{* * *}$ & $5.72^{* * *}$ & $24.44^{* * * *}$ & $4.77^{* * * *}$ & $3.86^{* *}$ & $12.39^{* * * *}$ & $3.84^{* * *}$ & $3.02^{* *}$ & $12.88^{* * * *}$ & $4.56^{* * *}$ & $1.71^{*}$ \\
\hline External regulation & 0.03 & $8.40^{* *}$ & 0.29 & $24.80^{* * *}$ & 0.17 & 2.15 & $17.32^{* * * *}$ & $3.54 * *$ & $6.50^{* * *}$ & $22.11^{* * * *}$ & $3.69^{* * *}$ & $5.42^{* * *}$ & $10.11^{* * * *}$ & $2 ; 57^{* *}$ & $4.95^{* * *}$ & $9.59 * * *$ & $2.81^{* *}$ & $2.69 * *$ \\
\hline Learning process & 0.44 & $8.94^{* *}$ & 0.02 & $14.26^{* * *}$ & 0.12 & 2.36 & $12.84^{* * * *}$ & $2.91^{* *}$ & $6.78^{* * *}$ & $24.07^{* * * *}$ & $2.68^{* *}$ & $5.08^{* * *}$ & $10.45^{* * * *}$ & $2.86^{* * *}$ & $4.65^{* * *}$ & $9.96^{* * *}$ & $2.62^{* * *}$ & $2.20^{*}$ \\
\hline Learning results & 0.11 & $5.84^{*}$ & 0.78 & $32.25 * * *$ & 0.37 & 1.64 & $14.57^{* * * *}$ & $3.23 * *$ & $5.44 * * *$ & $16.23^{* * * *}$ & $3.82^{* * *}$ & $5.09 * * *$ & $8.05^{* * * *}$ & $2.08^{*}$ & $4.40^{* * *}$ & $7.47^{* * * *}$ & $2.42^{* * *}$ & $2.87^{* *}$ \\
\hline \multicolumn{18}{|l|}{ Conceptions of learning } & 0.86 \\
\hline $\begin{array}{l}\text { Construction of } \\
\text { knowledge }\end{array}$ & $36.42^{* \ldots * *}$ & $14.91^{* * * *}$ & 0.14 & $32.27^{* * *}$ & 3.00 & 0.40 & $5.83^{* * *}$ & $4.70^{* * *}$ & $2.70^{*}$ & $6.87^{* * * *}$ & $3.38^{* *}$ & $3.86^{* *}$ & $3.59^{* * * *}$ & 0.83 & 1.52 & $2.88^{* * * *}$ & 1.14 & $2.95^{* *}$ \\
\hline Intake of knowledge & $6.80^{* * *}$ & 0.04 & 0.03 & $39.90 * * *$ & $6.02^{* *}$ & 0.80 & $4.00^{* * * *}$ & $3.71 * *$ & 2.80 ** & $5.81 * * *$ & $3.80^{* * * *}$ & $5.56^{* * *}$ & $2.67^{* * *}$ & 1.66 & 1.72 & $1.65^{* * *}$ & 1.45 & $3.25^{* *}$ \\
\hline Use of knowledge & $7.79^{* * *}$ & 0.03 & 0.03 & $22.08^{* * *}$ & 2.98 & 0.73 & $5.66^{* * * *}$ & $4.52^{* * *}$ & $3.46^{* *}$ & $8.76^{* * * *}$ & $3.13^{* *}$ & $3.30^{* *}$ & $4.63^{* * *}$ & 0.99 & 1.94 & $3.50^{* * *}$ & 0.91 & $3.12^{* *}$ \\
\hline $\begin{array}{l}\text { Stimulating } \\
\text { education }\end{array}$ & $34.91^{* * * *}$ & $12.08^{* * *}$ & 0.15 & $26.60^{* * *}$ & 3.15 & 0.37 & $5.34^{* * * *}$ & $3.67^{* *}$ & $2.92^{* *}$ & $7.10^{* * *}$ & $2.94 * *$ & $5.42^{* * *}$ & $4.40^{* * * *}$ & 1.21 & 1.69 & $2.97^{* * *}$ & 0.68 & $3.68^{* *}$ \\
\hline Cooperation & 2.71 & $16.29^{* * *}$ & 0.21 & $43.47^{* * * *}$ & 0.32 & 0.35 & $4.02^{* * *}$ & $3.86^{* * *}$ & $3.40^{* *}$ & $5.60^{* * * *}$ & $2.62^{* * *}$ & $4.68^{* * *}$ & $3.10^{* * * *}$ & 0.84 & 1.64 & $2.19^{* * *}$ & 1.49 & $3.50 * *$ \\
\hline \multicolumn{19}{|l|}{ Learning orientations } \\
\hline Personally interested & $9.29 * *$ & 0.21 & 0.20 & $25.74 * * *$ & 0.71 & 0.20 & $7.89^{* * * *}$ & $4.44 * * *$ & $3.37^{* *}$ & $17.24^{* * * *}$ & $3.80^{* * * *}$ & $3.80^{* *}$ & $6.21^{* * *}$ & 1.94 & 1.69 & $6.38^{* * *}$ & 1.69 & $2.68^{* *}$ \\
\hline Certificate directed & $12.83^{* * * *}$ & $26.98^{* * * k}$ & 0.74 & $23.85 * * *$ & 1.65 & 0.17 & $9.82^{* * * *}$ & $3.26 * * *$ & $3.24 * *$ & $13.34^{* * * *}$ & $3.83^{* * *}$ & $4.09 * * *$ & $4.39^{* * * *}$ & $2.35^{* *}$ & 1.27 & $5.95^{* * *}$ & $2.43^{* * *}$ & $1.68^{* *}$ \\
\hline Self-test directed & $24.72^{* * * *}$ & $15.34^{* * * *}$ & 0.30 & $36.66^{* * * *}$ & 0.43 & 0.04 & $10.63^{* * * *}$ & $2.13^{*}$ & $3.33^{* *}$ & $12.93^{* * * *}$ & $2.60^{* * *}$ & $3.80^{* *}$ & $4.66^{* * * *}$ & 0.86 & 1.76 & $4.39^{* * * *}$ & 0.54 & $2.30^{*}$ \\
\hline Vocation directed & 3.29 & 0.38 & 0.10 & $28.64 * * *$ & 1.77 & 0.07 & $12.28^{* * * *}$ & $2.99 * *$ & $3.74 * *$ & $11.00^{* * * *}$ & $2.92^{* * *}$ & $4.31^{* * *}$ & $4.88^{* * * *}$ & 1.42 & 1.18 & $4.54^{* * * *}$ & 0.52 & $3.06^{* * *}$ \\
\hline Ambivalent & $24.29^{* * * *}$ & $21.01^{* * * *}$ & $6.56^{*}$ & $4.39^{*}$ & 0.67 & 1.68 & $7.39^{* * * *}$ & $3.14 * *$ & $5.15^{* * * *}$ & $8.77^{* * * *}$ & $2.27^{*}$ & $3.74 * *$ & $4.45^{* * * *}$ & 1.95 & 0.59 & $6.17^{* * * *}$ & 1.76 & 0.49 \\
\hline Factor 1 & $5.28^{*}$ & $45.28^{* * * *}$ & 0.27 & $18.80^{* * * *}$ & 1.78 & 1.64 & $26.76^{* * * *}$ & $7.14^{* * * *}$ & $6.71^{* * * *}$ & $31.92^{* * * *}$ & $5.18^{* * * *}$ & $4.31^{* * *}$ & $14.69^{* * * *}$ & $4.83^{* * *}$ & $4.08^{* * * *}$ & $14.50^{* * * *}$ & $5.06^{* * *}$ & $2.43^{*}$ \\
\hline Factor 2 & $24.21^{* * *}$ & 3.61 & 0.04 & $40.19^{* * *}$ & 3.00 & 0.25 & $6.61^{* * *}$ & $4.53^{* * * *}$ & $3.18^{* * *}$ & $8.76^{* * * *}$ & $3.90^{* * *}$ & $4.83^{* * *}$ & $4.09^{* * * *}$ & 1.01 & 1.73 & $3.02^{* * * *}$ & 0.77 & $3.79^{* * *}$ \\
\hline Factor 3 & $27.32^{* * * *}$ & $27.77^{* * * *}$ & 3.69 & $12.70^{* * * *}$ & 0.01 & 1.67 & $10.38^{* * * *}$ & $3.05^{* *}$ & $4.69^{* * *}$ & $11.44^{* * * *}$ & $2.77^{* *}$ & $5.53^{* * *}$ & $5.07^{* * *}$ & 1.71 & 1.28 & $6.46^{* * * *}$ & $1.92^{*}$ & 0.62 \\
\hline
\end{tabular}




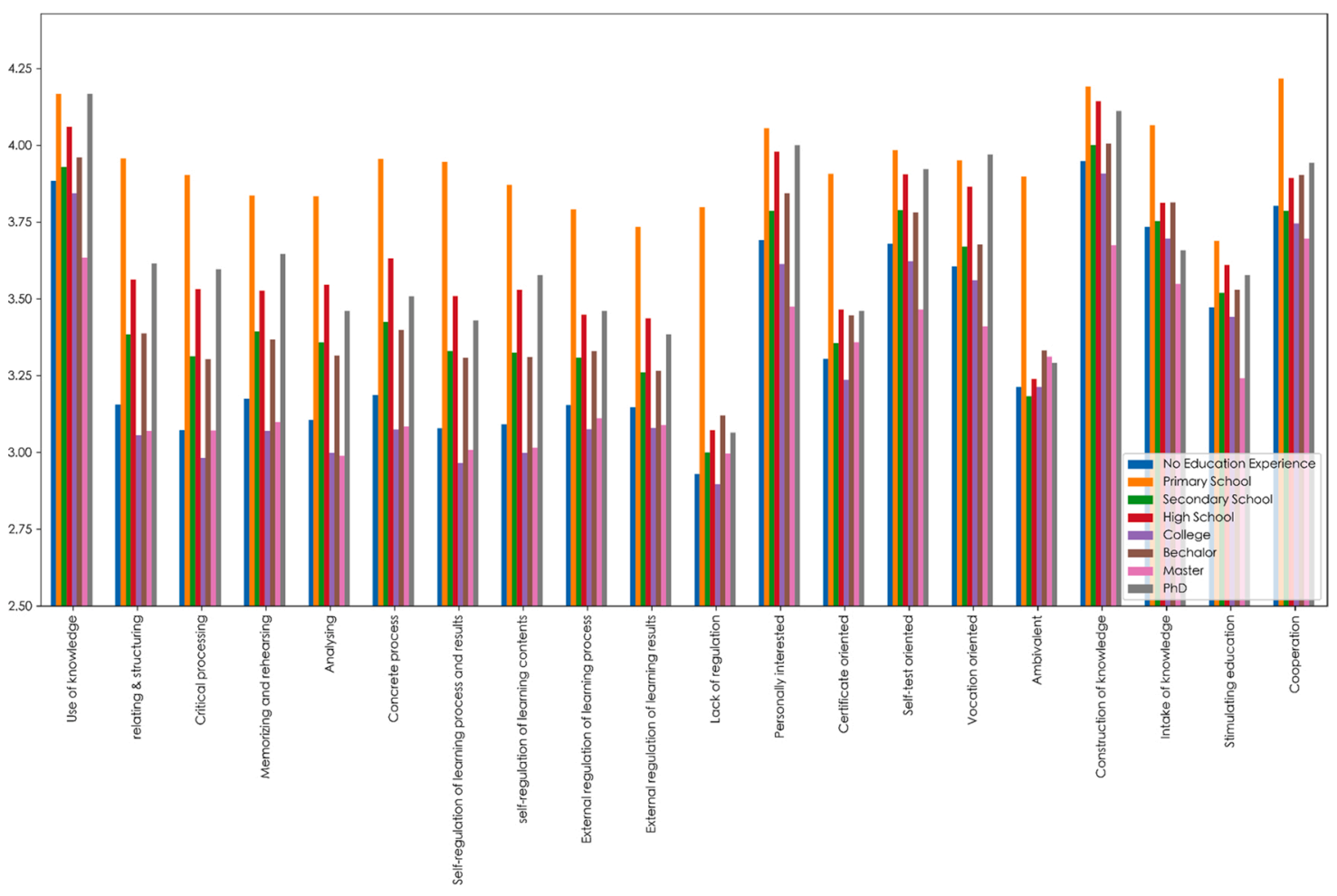

Fig. 1. Comparing means of learning pattern scales based on father's education level.

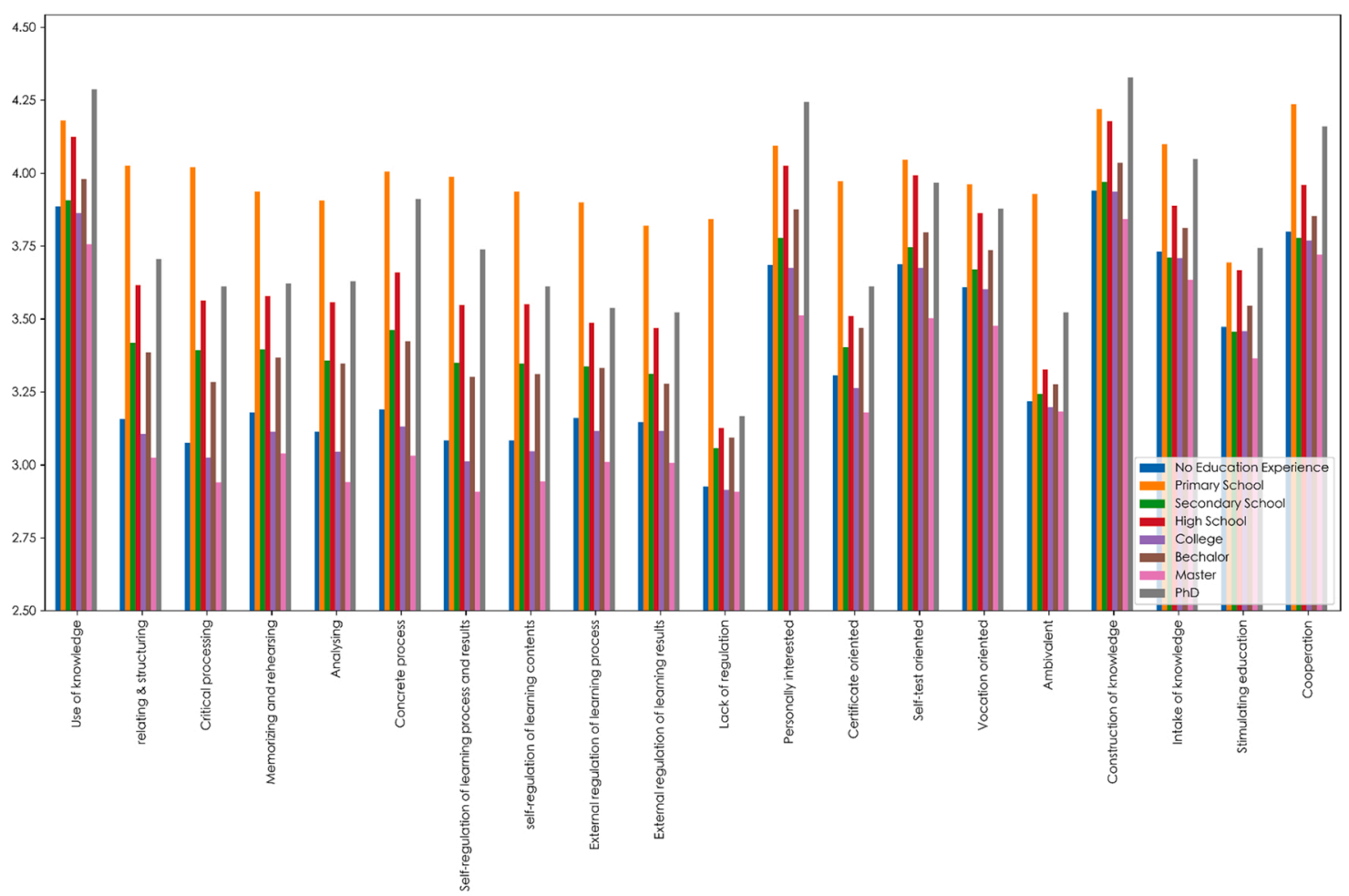

Fig. 2. Comparing means of learning patterns based on mother's education level.

regulation strategies, while mothers' jobs were significantly associated with most scales of learning patterns of such students except lack of regulation and ambivalent orientation.

Regarding relationships of personal and contextual factors with the three clustered learning patterns, gender significantly affected the learning patterns of secondary school students, as well as the Factor 1 and Factor 3 learning patterns of high school students, while showing little or no effect on the learning patterns of college students. The learning patterns of secondary school students tended to vary with different ages, while this variation disappeared for high school and college students. Parents' educational levels had significantly close relationships with the learning patterns of the three groups of students. 


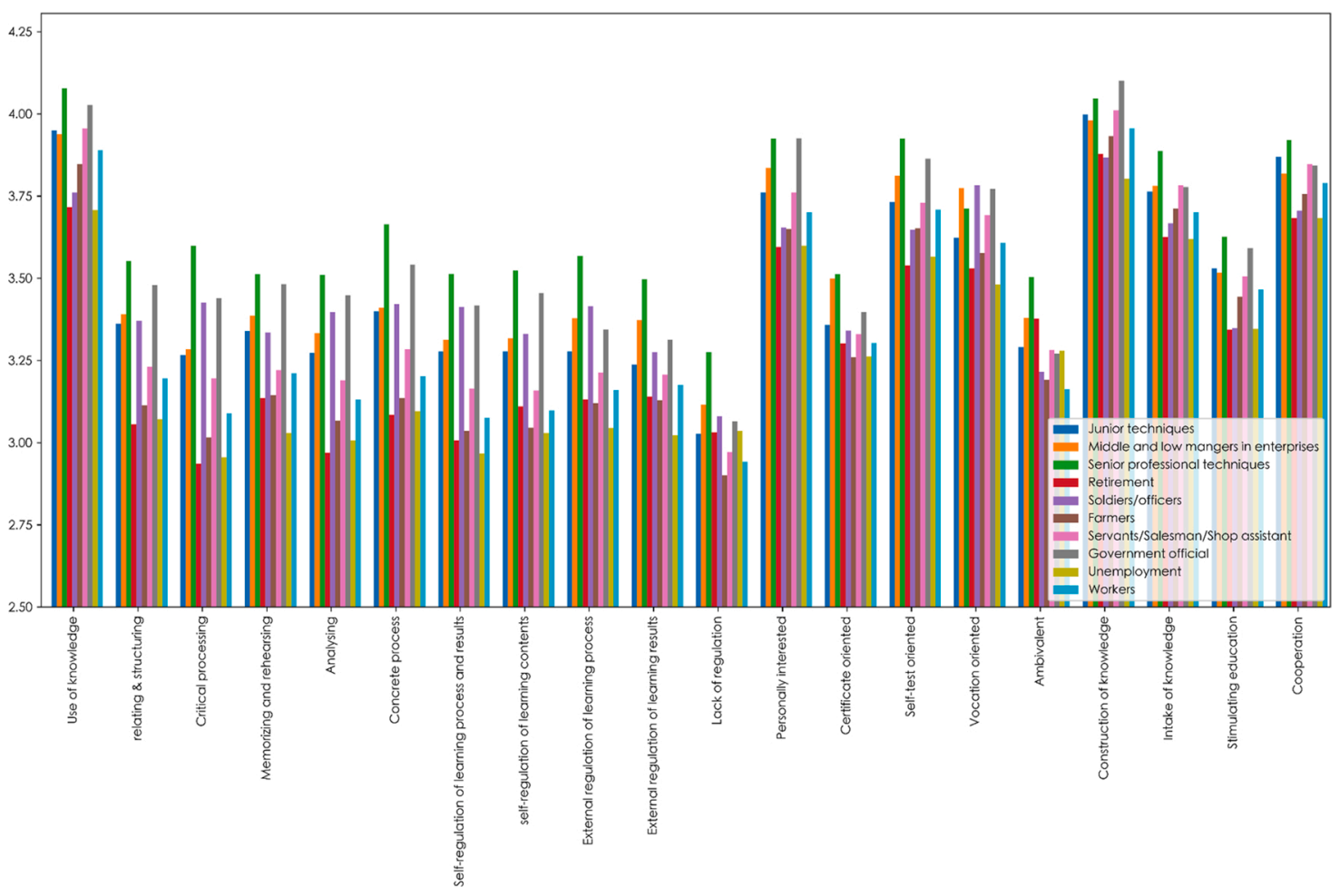

Fig. 3. Comparing means of learning patterns based on father's job.

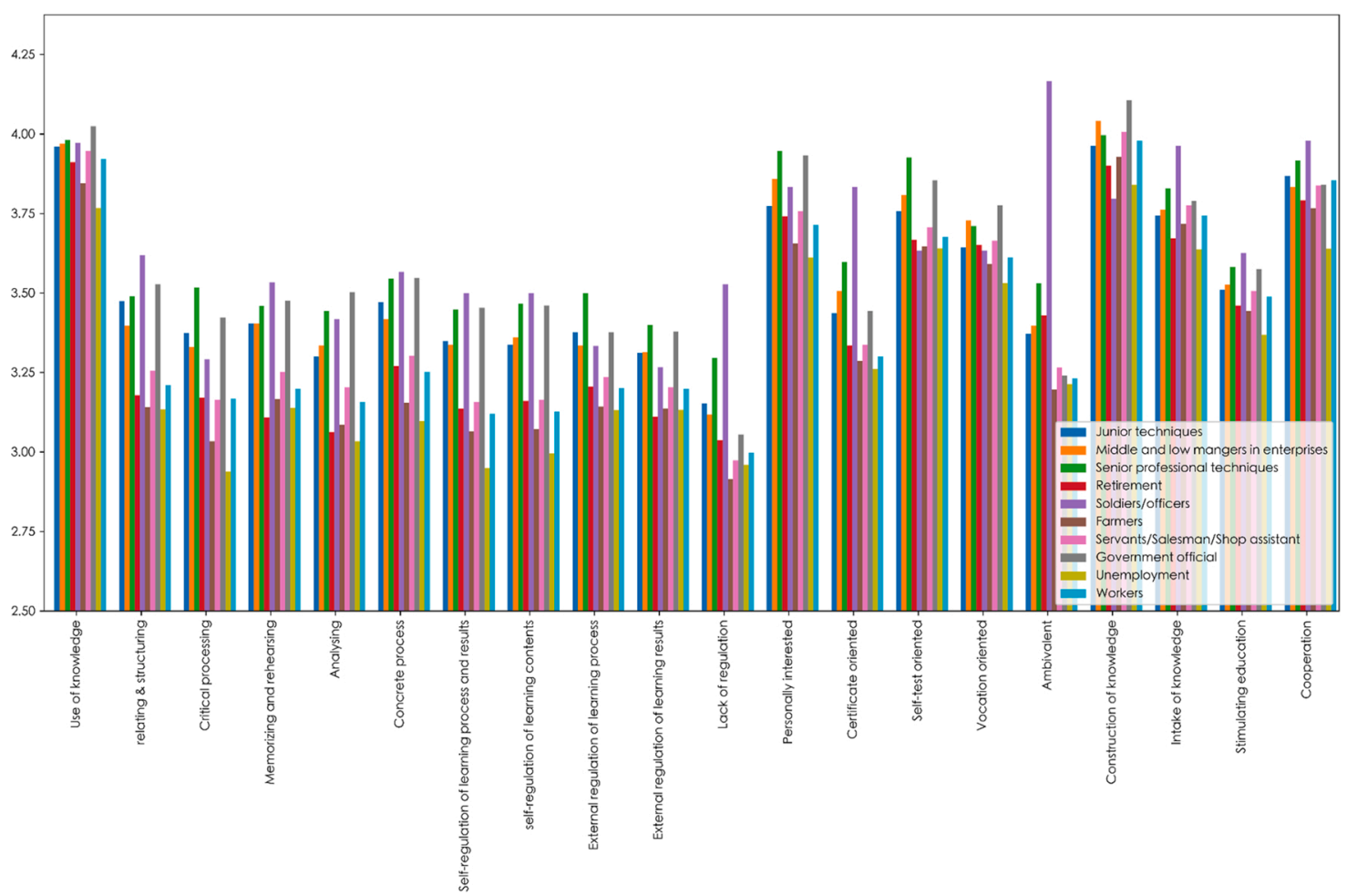

Fig. 4. Comparing means of learning patterns based on mother's job.

Parents' jobs were significantly relevant to the three learning patterns of secondary school students, while they were only meaningful to the Factor 1 pattern of high school and college students.

\section{Discussion}

This study showed that the ILS worked well with secondary school students, high school students and college students. In previous studies, the ILS was used primarily in higher education, while alphas reported were low when tested on secondary school students (Slaats, Lodewijks, 
\& van der Sanden, 1999). The evidence obtained in our research indicated that the usage of the ILS could be extended to school students. There are some typical features of the learning patterns of students in mainland China. They tended to address subject content by connecting it to their daily experience, to regulate their learning processes and results with the assistance of external factors, and to view learning as a means of constructing knowledge. Compared to the mean scores reported in previous studies, the learning patterns adopted by students in mainland China were generally different from those adopted in Hong Kong or Indonesia, although they shared similarities with Venezuelan students in terms of cognitive processing strategies and conception of learning, and with students in the Netherlands in terms of regulation strategies (see Vermunt et al., 2014). This provides empirical evidence that learning stereotypes, like those of the Asian learner or the Western learner, are inappropriate, which was comparable to the findings of Marambe et al. (2012).

The answer to the first research question is that the secondary school, high school and college students generally differed from each other in terms of their learning patterns. The main differences between the three student groups lay in learning strategies and activities, while the variations on conceptions and orientations of learning amongst the groups were small. College students outperformed school students in critical processing strategies and regulation strategies. This finding is compatible with the longitudinal study reported by Coertjens et al. (2017) that students on average increased self-regulation strategies and deep learning during the transition periods from secondary school to higher education. With regard to learning orientations, secondary school students tended to study out of interest and for the purpose of self-development; high school students tended to study to pass examinations; while college students primarily studied to gain knowledge in order to cope with vocational challenges. This is probably due to the requirements and objectives of the different educational sectors. Secondary education pays attention to the cultivation of students' ability to comprehend and emphasizes mastery of basic knowledge; a pressing learning goal for high school students is to perform well in college entrance examinations or applications; higher education has high requirements with respect to students' deep learning and self-regulation, and college students face pressure as a result of employment problems (OECD, 2016). Notably, older students seem to have higher scores on most scales than younger ones. One explanation could be that this is due to desirability effects in the responses. However, a more reasonable explanation to us seems to be that older students, especially college students, have a clearer understanding of their learning patterns than school students (Zhang, 2013). Students at the higher stages of education may also be more capable than those at the lower stages of flexibly switching between patterns in order to adapt optimally to a given situation.

The second research question referred to similarities and differences in the dimensionality of learning patterns observed in the three student groups. The internal structure of learning patterns was similar for secondary school and high school students, but was different from that of college students. School students were characterized by meaningdirected learning, undirected learning and passive learning patterns, while college students were characterized by action-directed learning, passive-idealistic and passive-motivated learning patterns. The clustered learning patterns of the college students has also been identified in other regions/countries (see Marambe et al., 2012; Vermunt et al., 2014). For example, the action-directed learning pattern was found in Indonesian college students, with high loadings on processing strategies, self-regulation strategies and external regulation strategies. The passive-idealistic pattern was reported in studies of Sri Lankan and Indonesian students, as students were full of conceptions about learning while being incapable of developing suitable strategies to cope with learning tasks. A typical feature found in the three groups of students was a split in strategies and views loading on different factors. This indicates that the learning strategies that the Chinese students habitually used were different from what they perceived learning should be. There seems to be a mismatch between the activities expected by the learning environment, which is a student-centred approach, and the strategies adopted in daily teaching and learning, primarily a teacher-centred approach. In recent years, pedagogical reform has expanded in many countries globally, including China (Howe, Hennessy, Mercer, Vrikki, \& Wheatley, 2019). One essential objective of the reform lies in the transformation of teaching approaches and the encouragement of the development of active learning strategies. Students are expected to actively participate in classroom learning, exploring knowledge, increasing understanding and developing critical thinking. Yet in practice, students might experience a friction between learning expectations and the strategies to cope with examinations, which has also been reported by Marambe et al. (2012).

With regard to the third question, the influence of gender and age on learning patterns was quite different for each of the three student groups, but parental effects tended to be equally strong amongst the groups. Boys and girls in secondary and high schools varied in many aspects of learning patterns, but this distinction was less apparent in college students. This finding is similar to that reported by Law and Meyer (2011) with regard to Hong Kong students, namely, that there was little or no difference in learning patterns between male and female college samples compared to school students. Secondary school students of different ages differ a great deal from each other with regard to the learning patterns adopted. For high school students, the variations in age tended to have only a small influence on their learning patterns, with only three scales (i.e. relating and structuring strategy, analysing strategy and intake of knowledge) showing significant results. This influence diminished further in the case of college students, with almost no scales showing a significant relationship with age. The changes in teaching and learning environment within an education sector are often much smaller than between sectors (Vermunt et al., 2014). Previously, there has been an argument that students' learning patterns tend to be similar when the environment remains more or less constant (Gijbels et al., 2014; Vermunt \& Donche, 2017). Our findings provide more evidence that students' learning patterns are likely to be different, even when their environments are similar and remain constant. This variation is typical in lower stages of education, whose students are in their formative years, probably under the age of 16 .

Parents' education levels and jobs had strong relationships with learning patterns amongst the three groups of students. The distinctions between students with different parental education levels were particularly obvious in terms of critical processing, analysing, self-regulation strategies, certificate-directed orientation, vocation-directed orientation and construction of knowledge. The distinctions between students whose parents occupied different jobs were mainly in cognitive processing strategies and regulation strategies. Students whose parents had received high academic qualifications were more likely to adopt a meaning-directed pattern or action-directed pattern than those whose parents had received no education at all or only at a low level. Students of such parents were more likely to learn passively or in an undirected way. Generally, we found that students whose parents' jobs required some technical skill and knowledge (e.g. senior professional technicians, governmental officials and senior executives of enterprises) were more likely to adopt a meaning-directed learning pattern or action-directed pattern, while those whose parents' jobs required less technical skill and knowledge (e.g. servants, the retired or the unemployed) tended to adopt an undirected learning pattern. Our findings indicate that parental influence is important when it comes to the development of learning patterns. This is probably due to the fact that parents who have received a high level of education or are employed in jobs requiring high technical skills are more often involved in their children's education, and are armed with more knowledge or the means to help their children (Marambe et al., 2012). 


\section{Conclusion, contributions and implications}

This paper seems to be the first to compare learning patterns of students from different educational sectors, namely, secondary school, high school and college. The empirical findings show that these three groups of students differ in their adoption of learning patterns; dimensionalities of learning patterns observed in secondary school and high school students are similar, but are different from those of college students; these students' learning patterns differ from each other in relation to personal (i.e. gender and age) factors, but tend to have similar strong relationships with parents' education levels and parents' jobs. The current study has focused on Chinese students, and selected students from three stages of education, namely, secondary school, high school and college, for comparison purposes. Future studies could compare learning patterns across a wider variety of educational contexts, for example, from secondary school students to $\mathrm{PhD}$ students. Also, more research is needed to conduct comparisons with other countries or regions. A cross-educational together with a cross-cultural study would help to develop a more comprehensive understanding of students' learning patterns. Another necessary approach is to conduct longitudinal studies and track how students' learning patterns change not only during transitions between educational sectors, but also within an educational sector.

Despite the above limitations, the current work has made contributions to the field of learning patterns in a number of ways. Firstly, previous studies with respect to style, including learning patterns, are mainly been conducted with students in higher education, while less is known about the strategies and views about learning of younger students. Vermunt and Donche (2017) call for studying learning patterns in wider range of contexts and populations beyond the first years of higher education. We have extended the study of learning patterns to secondary and high school students. Good internal consistency was observed, indicating the suitability of ILS with respect to research on younger students, for example, those aged between 14 and 17 .

Secondly, the current work enhances our understanding of the consistency and variability of learning patterns across educational sectors. The main variability lays in the use of learning strategies, with students from the higher education sector showing a higher tendency to adopt various cognitive processing and regulation strategies, while at the same time being more likely to be characterized with the meaning-directed pattern than those from lower sectors. College students seemed to be capable of greater flexibility with respect to the adoption of learning patterns than school students. With this knowledge, teachers and tutors will be able to provide better support for students as they adapt to a new educational environment and to assist them in successfully moving on to higher education. Special attention should be paid to the cultivation of deep-processing strategies and capacities for self-regulation. Furthermore, pattern flexibility is important, and students should increase their skills in order to flexibly switch between patterns and to choose the most appropriate one(s) in a given situation. Apart from teaching students what to learn, teachers should guide learners to reflect on their ways of thinking and learning, and to increase their capacity to discern the most appropriate way of working and learning in response to the demands of a specific task.

Thirdly, we found that parents' educational level and jobs are important explanatory factors regarding the variations in the learning patterns of all three student groups. Previously, scholars have focused on the contextual factors within schools or universities, for example, teaching strategies and learning environment, but few of them have considered the function of families. Our findings suggest that parents play an important role in the development of their children's learning patterns, in shaping how they think and learn and in identifying what motivates them. Parents should pay attention to how their children think and learn, provide strategic support in relation to how to process information and regulate their learning, and direct them to develop appropriate learning conception and orientation. There should be guidance for parents, particularly those who have received little education or have been employed in jobs requiring low technical skills, about how to help their children develop cognitive processing strategies, enhance regulation strategies and increase motivation.

\section{Funding}

This work has been supported by the Guangdong Philosophy and Social Science Foundation (GD18XJY23) and National Natural Science Foundation of China (No. 61907017).

\section{Declaration of Competing Interest}

The authors report no declarations of interest.

Appendix A. Scales of the Inventory of Learning Styles (ILS) and their content (from Vermunt \& Vermetten, 2004)

\begin{tabular}{|c|c|}
\hline Parts and scales of the ILS & Description of content \\
\hline \multicolumn{2}{|l|}{ Processing Strategies } \\
\hline \multicolumn{2}{|l|}{ Deep processing } \\
\hline Relating \& structuring & Relating elements of the subject matter to each other and to prior knowledge; structuring these elements into a whole \\
\hline Critical processing & $\begin{array}{l}\text { Forming one's own view on the subjects that are dealt with, drawing one's own conclusions, and being critical of the conclusions drawn by textbook } \\
\text { authors and teachers }\end{array}$ \\
\hline \multicolumn{2}{|l|}{ Stepwise processing } \\
\hline $\begin{array}{l}\text { Memorising \& } \\
\text { rehearsing }\end{array}$ & Learning facts, definitions, lists of characteristics, and the like by heart by rehearsing them \\
\hline Analysing & Going through the subject matter in a stepwise fashion and studying the separate elements thoroughly, in detail and one by one \\
\hline Concrete processing & Concretising and applying subject matter by connecting it to one's own experiences and by using in practice what one learns in a course \\
\hline \multicolumn{2}{|l|}{ Regulation strategies } \\
\hline \multicolumn{2}{|l|}{ Self-regulation } \\
\hline $\begin{array}{l}\text { Learning process \& } \\
\text { results }\end{array}$ & $\begin{array}{l}\text { Regulating one's own learning processes through regulation activities like planning learning activities, monitoring progress, diagnosing problems, } \\
\text { testing one's outcomes, adjusting, and reflecting }\end{array}$ \\
\hline Learning content & Consulting literature and sources outside the syllabus \\
\hline \multicolumn{2}{|l|}{ External regulation } \\
\hline Learning process & $\begin{array}{l}\text { Letting one's own learning processes be regulated by external sources, such as introductions, learning objectives, directions, questions, or assignments of } \\
\text { teachers or textbook authors }\end{array}$ \\
\hline Learning results & Testing one's learning outcomes by external means, such as the tests, assignments, and questions provided \\
\hline Lack of regulation & Monitoring difficulties with the regulation of one's own learning processes \\
\hline
\end{tabular}


(continued)

\begin{tabular}{|c|c|}
\hline Parts and scales of the ILS & Description of content \\
\hline \multicolumn{2}{|l|}{ Conceptions of learning } \\
\hline $\begin{array}{l}\text { Construction of } \\
\text { knowledge }\end{array}$ & Learning viewed as constructing one's own knowledge and insights. Most learning activities are seen as tasks of students. \\
\hline Intake of knowledge & Learning viewed as taking in knowledge provided by education through memorizing and reproducing; other learning activities are tasks of teachers. \\
\hline Use of knowledge & $\begin{array}{l}\text { Learning viewed as acquiring knowledge that can be used by means of concretising and applying. These activities are seen as tasks of both students and } \\
\text { teachers. }\end{array}$ \\
\hline Stimulating education & Learning activities are viewed as tasks of students, but teachers and textbook authors should continuously stimulate students to use these activities. \\
\hline Cooperative learning & Attaching a lot of value to learning in co-operation with fellow students and sharing the tasks of learning with them \\
\hline \multicolumn{2}{|l|}{ Learning orientations } \\
\hline Personally interested & Studying out of interest in the course subjects and to develop oneself as a person \\
\hline Certificate-oriented & Striving for high study achievements; studying to pass examinations and to obtain certificates, credit points, and a degree \\
\hline Self-test-oriented & Studying to test one's own capabilities and to prove to oneself and others that one is able to cope with the demands of higher education \\
\hline Vocation-oriented & Studying to acquire professional skill and to obtain a(nother) job \\
\hline Ambivalent & A doubtful, uncertain attitude toward the studies, one's own capabilities, the chosen subject area, the type of education, etc. \\
\hline
\end{tabular}

\section{References}

Alves de Lima, A., Bettati, M., Baratta, S., Falconi, M., Sokn, F., Galli, A., et al. (2006). Learning strategies used by cardiology residents: Assessment of learning styles and their correlations. Education for Health, 19(3), 289-297.

Catrysse, L., Coertjens, L., Donche, V., van Daal, T., \& Van Petegem, P. (2015). The impact of personality and motivation on the development of learning strategies. Pedogogische studien, 92(5), 308-323.

Coertjens, L., Donche, V., Maeyer, S, D., Van Daal, T., \& Van Petegem, P. (2017). The growth trend in learning strategiesvduring the transition from secondary to higher education in Flanders. Higher Education, 73, 499-518.

De Clerca, M., Galand, B., \& Frenay, M. (2013). Chicken or the egg: Longitudinal analysis of the causal dilemma between goal orientation, self-regulation and cognitive processing strategies in higher education. Studies in Educational Evaluation, 39(1), 4-13.

Donche, V., \& Gijbels, D. (2013). Understanding learning pattern development in higher education: A matter of time, context and measurement. Studies in Educational Evaluation, 39(1), 1-3.

Donche, V., De Maeyer, S., Coertjens, L., van Daal, T., \& van Petegem, P. (2013). Differential use of learning strategies in first-year higher education: The impact of personality, academic motivation, and teaching strategies. The British Journal of Educational Psychology, 83(2), 238-251.

Eaves, M. (2009). Learning styles technology and supporting overseas learners. Multicultural Education \& Technology Journal, 3(1), 61-73.

Evans, C., \& Vermunt, J. D. (2013). Styles, approaches, and patterns in student learning. The British Journal of Educational Psychology, 83(2), 185-195.

Ferla, J., Valcke, M., \& Schuyten, G. (2008). Relationships between student cognitions and their effects on study strategies. Learning and Individual Differences, 18(2), 271-278.

Fryer, L. K., Ainley, M., \& Thompson, A. (2016). Modelling the links between students' interest in a domain, the tasks they experience and their interest in a course: isn't interest what university is all about? Learning and Individual Differences, 50, 157-165.

Gijbels, D., Donche, V., Richardson, J. T. E., \& Vermunt, J. D. (2014). Learning patterns in higher education: Dimensions and research perspectives. New York, NY: Routledge.

Heikkilä, A., Niemivirta, M., Nieminen, J., \& Lonka, K. (2011). Interrelations among university students' approaches to learning, regulation of learning, and cognitive and attributional strategies: A person-oriented approach. Higher Education, 61(5), 513-529.

Howe, C., Hennessy, S., Mercer, N., Vrikki, M., \& Wheatley, L. (2019). Teacher-student dialogue during classroom teaching: Does it really impact upon student outcomes? The Journal of the Learning Sciences, 1-64.

Law, D. C. (2009). The adaptation, validation and application of a research instrument for investigating the relationships between students' perceptions of the learning context and students' learning patterns in post-secondary education of Hong Kong. EdD Thesis. United Kingdom: University of Durham.
Law, D. C. S., \& Meyer, J. H. F. (2011). Adaptation and validation of the course experience questionnaire in the context of post-secondary education in Hong Kong. Quality Assurance in Education, 19(1), 79-97.

Lindblom-Ylänne, S., \& Lonka, K. (2000). Dissonant study orchestrations of highachieving university students. European Journal of Psychology of Education, 15(1), 19-32.

Lonka, K., Olkinuora, E., \& Mäkinen, J. (2004). Measuring studying and learning in higher education-Conceptual and methodological issues. Educational Psychology Review, 16(4), 301-323.

Marambe, K. N., Vermunt, J. D., \& Boshuizen, H. P. (2012). A cross-cultural comparison of student learning patterns in higher education. Higher Education, 64(3), 299-316.

Martínez-Fernández, J. R., \& Vermunt, J. D. (2015). A cross-cultural analysis of the patterns of learning and academic performance of spanish and latin-american undergraduates. Studies in Higher Education, 40(2), 278-295.

OECD. (2018). Education at a glance: OECD indicators. https://www.education.ie/en /Publications/Statistics/International-Statistical-Reports/eag-2018-briefing-note. pdf.

OECD. (2016). Education in China, a snapshot. https://www.oecd.org/china/Educa tion-in-China-a-snapshot.pdf.

Slaats, J. A. M. H., Lodewijks, J. G. L. C., \& van der Sanden, J. M. M. (1999). Learning styles in secondary vocational education: Disciplinary differences. Learning and Instruction, 9, 475-492.

Smith, B., Ray, G. E., Stefurak, T., \& Zachar, P. (2007). College student evaluations of parent-Child disciplinary situations. Journal of Family Violence, 22(8), 757-767.

Stump, G. S., Husman, J., \& Corby, M. (2014). Engineering students' intelligence beliefs and learning. Journal of Engineering Education, 103(3), 369-387.

Timarova, S., \& Salaets, H. (2011). Learning styles, motivation and cognitive flexibility in interpreter training: Self-selection and aptitude. Interpreting, 13(1), 31-52.

Vermunt, J. D. (1998). The regulation of constructive learning processes. The British Journal of Educational Psychology, 68(2), 149-171.

Vermunt, J. D. (2005). Relations between student learning patterns and personal and contextual factors and academic performance. Higher Education, 49(3), 205-234.

Vermunt, J. D. (2020). Surveys and retrospective self-reports to measure strategies and strategic processing. In D. L. Dinsmore, L. K. Fryer, \& M. M. Parkinson (Eds.), Handbook of strategies and strategic processing (pp. 259-274). New York: Routledge.

Vermunt, J. D., \& Donche, V. (2017). A learning patterns perspective on student learning in higher education: State of the art and moving forward. Educational Psychology Review, 29(2), 269-299.

Vermunt, J. D., \& Vermetten, Y. J. (2004). Patterns in student learning: Relationships between learning strategies, conceptions of learning, and learning orientations. Educational Psychology Review, 16(4), 359-384.

Vermunt, J. D., Bronkhorst, L., \& Martinez-Fernandez, R. (2014). The dimensionality of student learning patterns in different cultures. In D. Gijbels, V. Donche,

J. T. Richardson, \& J. D. Vermunt (Eds.), Learning patterns in higher education: Dimensions and research perspectives (pp. 33-55). Abingdon, UK: Routledge.

Zhang, L. F. (2013). The malleability of intellectual styles. Cambridge University Press. 